\title{
The Research of Jet Flame Extinguishing Process
}

\author{
Wenliang Guo \\ College of Mechanical Engineering, Taiyuan University of \\ Technology, Taiyuan 030024, China
}

\begin{abstract}
The flame used in combustion flame spraying is typical of a high-temperature free jet. The flow fields of free jets are multi-phase flows that couple the mass and heat transfer. This work develops an analytical method to describe free combustion spray jets. The aim of the research is to develop a fully understanding of the characteristics of free-flame jets. Experimental measurements were carried by a unique highspeed continuous CCD camera.
\end{abstract} camera

Key words-flame jet; combustion spray jets; high-speed CCD

\section{INTRODUCTION}

The firing of a thermal spray flame is typical of a laminar diffusion combustion jet. Laminar jet flames have been the subject of fundamental research and can be used to develop an understanding of thermal spray flames. In a free laminar jet, the fuel stream is usually partially premixed with air. A primary concern in the analysis of thermal spray system is the flame geometry and the parameters that control flame size and shape. The characteristic time of flame combustion has been determined by the flame-extinguishing experiments.

\section{NON-REACTING CONSTANT-DENSITY LAMINAR JET}

\section{A. Physical description}

It is necessary to consider a simple case of non-reacting laminar jet of a fluid (fuel) flowing into an infinite reservoir of a quiescent fluid (atmosphere air). This simple case develops an understanding of the basic flow and diffusional processes that occur in laminar jets[1].
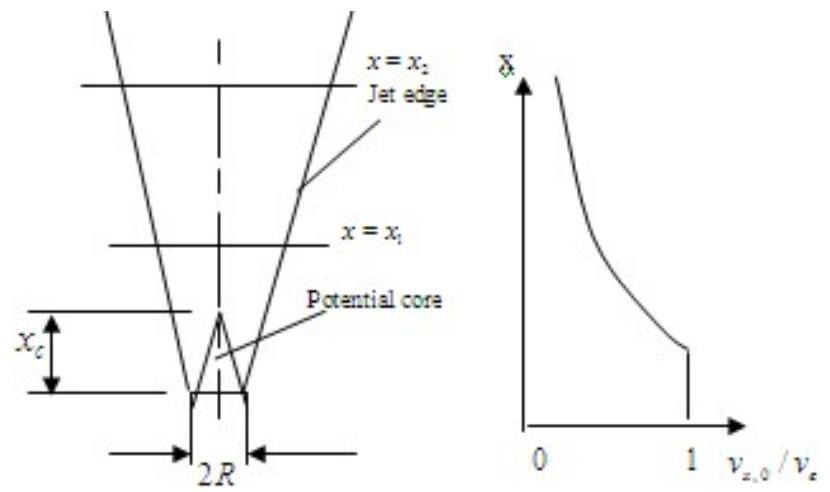

Fig. 1 Non-reacting, laminar fuel jet issuing into an infinite reservoir of quiescent ai

\author{
Zheng Guo \\ HSBC Bank, Hong Kong
}

Fig. 1 illustrates the essential features of a fuel jet issuing from a nozzle with radius $R$ into still air. The velocity profile was assumed to be uniform at the tube exit. Close to the nozzle exit, there is a region called the potential core of the jet. In the potential core, the velocity and nozzle-fluid mass fraction remain unchanged from their nozzle-exit values and are uniform in this region.

In the region between the potential core and the jet edge, the velocity and fuel concentration (mass fraction) decrease monotonically to zero at the edge of the jet. Beyond the potential core $\left(x>x_{c}\right)$, the effects of viscous shear and mass diffusion are active across the whole width of the jet.

The initial jet momentum is conserved throughout the entire flow field. As the jet issues into the surrounding air, some of its momentum is transferred to the air. While more and more quantities of air are entrained into the jet, the velocity of the jet decreases as the jet proceeds downstream. This idea can be expressed by using an integral form of momentum conservation [2]:

$$
2 \pi \int \rho(r, x) v_{x}^{2}(r, x) r d r=\rho_{e} v_{e}^{2} \pi R^{2}
$$

Where $\rho_{e}$ and $v_{e}$ are the density and velocity of the fuel at the nozzle exit, respectively. Fig. 1 illustrates the decay of the centerline velocity with distance beyond the potential core.

\section{B. Solution}

The velocity field can be obtained by assuming the profiles to be similar. The radial distribution of $v_{x}(r, x)$, when normalized by the local centerline velocity $v_{v_{x}}(0, x)$, is a universal function that depends only on the similarity variable, $r / x$. The dimensionless centreline velocity decay is obtained by setting $r=0$

$$
v_{x, 0} / v_{e}=0.375\left(\rho_{e} v_{e} R / \mu\right)(x / R)^{-1} .
$$

Eq. 2 shows that the velocity decays inversely with axial distance and is proportional to the jet Reynolds number $\left(\mathrm{Re}_{j} \equiv \rho_{e} v_{e} R / \mu\right)$. Eq. 2 is not valid near the nozzle, since $v_{x, 0} / v_{e}$ could not exceed unity. The centreline velocity decay pattern predicted by Eq. 2 is shown in Fig. 2. 


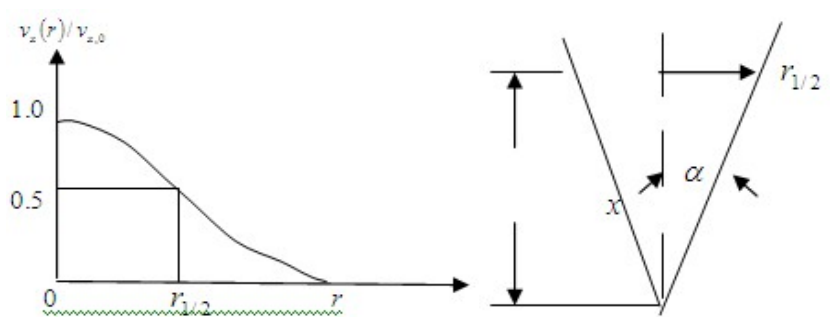

Fig. 2 Definitions of jet spreading angle $\alpha$

Other important parameters used to characterize jets are the spreading rate and spreading angle $\alpha$. The idea of the jet half-width, $r_{1 / 2}$ is introduced to define the spreading rate and spreading angle. The jet half-width is simply the radial location where the jet velocity has decayed to one half of its centreline value (Fig. 2). An expression for $r_{1 / 2}$ can be derived by setting $r_{1 / 2}$ to be one half and solving for $r\left(=r_{1 / 2}\right)$. The ratio of the jet half-width to the axial distance $x$ is termed the jet spreading rate. Thus,

$$
r_{1 / 2} / x=2.97\left(\frac{\mu}{\rho v_{e} R}\right)=2.97 \operatorname{Re}_{j}^{-1}
$$

and

$$
\alpha \equiv \tan ^{-1}\left(r_{1 / 2} / x\right)
$$

Eq. 3 and 4 reveal that high- $\operatorname{Re}_{j}$ jets are narrow, while low- $\operatorname{Re}_{j}$, jets are wide.

\section{JET FLAME PHYSICAL DESCRIPTIONS}

Fig.3 shows part of pre-mixed flame jet in the extinguishing process of the thermal spray flame. Because the fuel and air are pre-mixed, the flame is brighter and the average flame length is easier to observe. In non-premixed combustion flame spray, there is soot formation in the experiments.

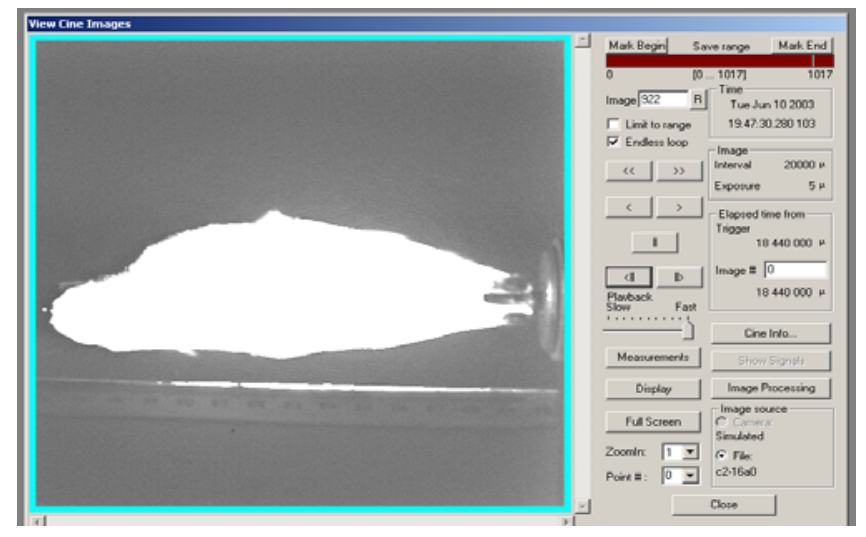

Fig. 3a Combustion thermal spray jet length in the extinguishing process ( 0 $\mathrm{ms})$

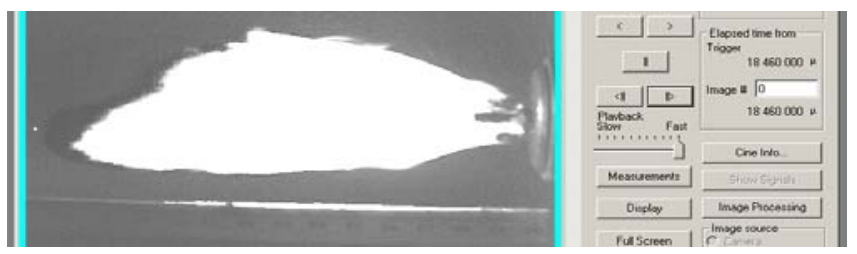

Fig. 3b Combustion thermal spray jet length the extinguishing process (20 ms)

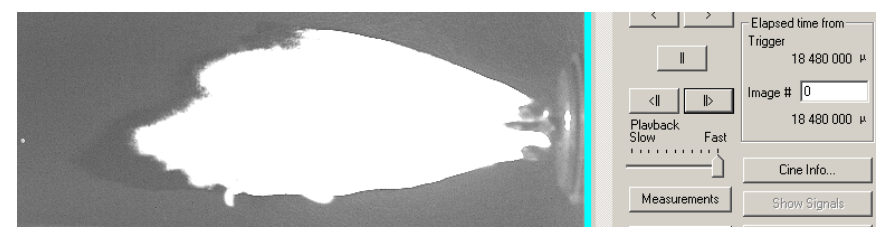

Fig. 3c Combustion thermal spray jet length in the extinguishing process (40 ms)

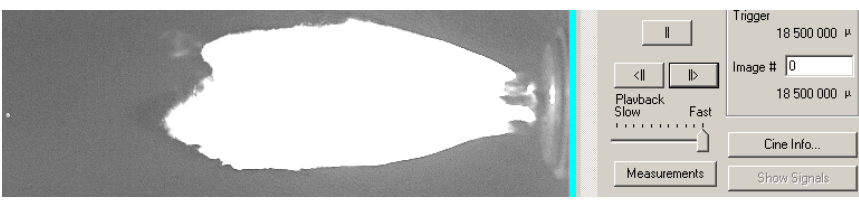

Fig. 3d Combustion thermal spray jet length in the extinguishing process (60 ms)

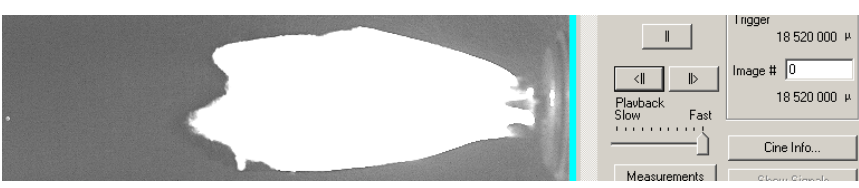

Fig. 3e Combustion thermal spray jet length in the extinguishing process (80 ms)

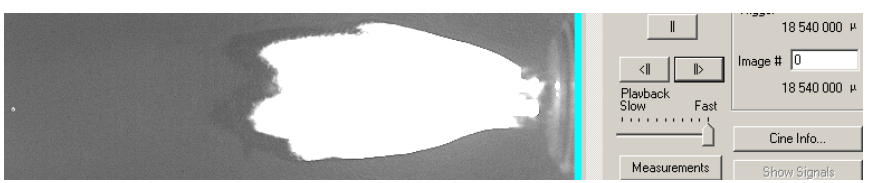

Fig. 3f Combustion thermal spray jet length in the extinguishing process (100 ms)

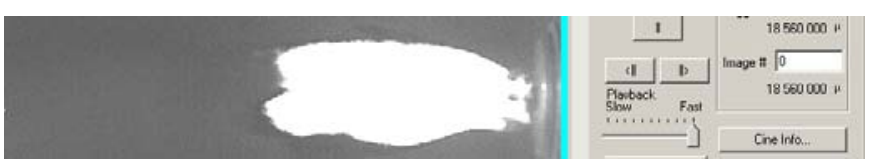

Fig. 3g Combustion thermal spray jet length in the extinguishing process (120 ms)

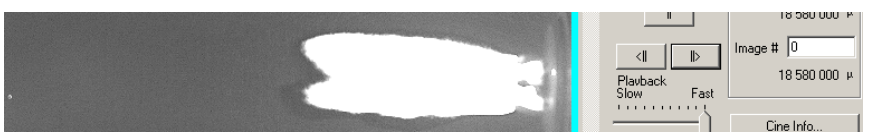

Fig. 3h Combustion thermal spray jet length in the extinguishing process (140ms)

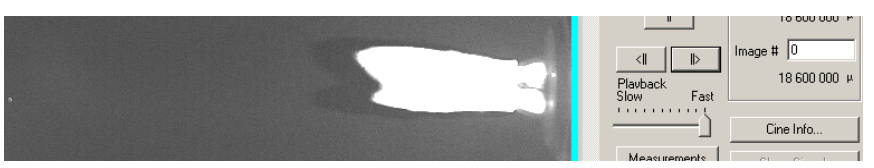

Fig. 3i Combustion thermal spray jet length in the extinguishing process (160 ms)

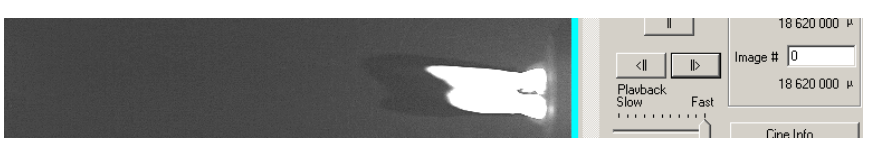

Fig. 3j Combustion thermal spray jet length in the extinguishing process (180 ms) 


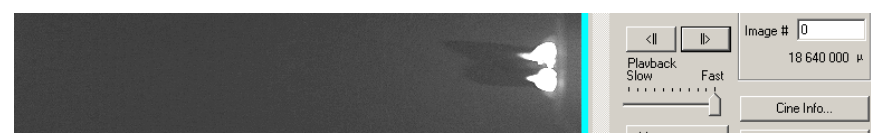

Fig. 3k Combustion thermal spray jet length in the extinguishing process (200 ms)

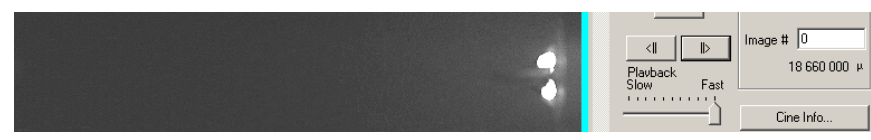

Fig. 3l Combustion thermal spray jet length in the extinguishing process (220 ms)

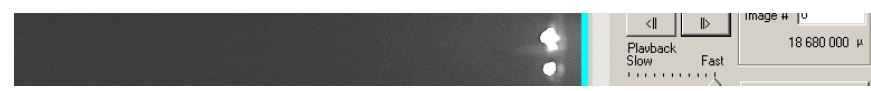

Fig. 3m Combustion thermal spray jet length in the extinguishing process (240 ms)

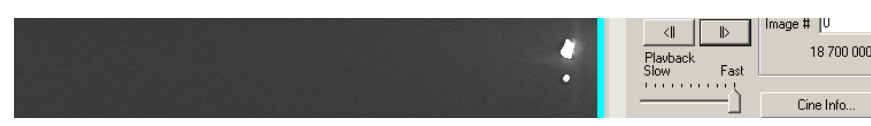

Fig. 3n Combustion thermal spray jet length in the extinguishing process (260 ms)

The feature of laminar jet diffusion flames is the relationship between flame length and initial conditions. The flame length is then obtained when $r$ equals zero:

$$
L_{f} \approx \frac{3}{8 \pi} \frac{Q_{F}}{D Y_{F, \text { stoic }}}
$$

The flame length is proportional to the volumetric flowrate and inversely proportional to the stoichiometric fuel mass fraction.

\section{SIMPLIFIED THEORETICAL DESCRIPTIONS FOR FLAME JETS}

The earliest theoretical description of the laminar jet diffusion flame is that of Burke and Schumann [3] published in 1928. Their theory predicted flame lengths reasonably well for axisymmetric (circular-port) flames. This good agreement led other investigators to refine the original theory. More complete mathematical descriptions can be found in advanced texts [4] and original references [5].

\section{CALCULATED RESULTS FOR NON-REACTING ACETYLENE JETS}

A jet of acetylene $\left(\mathrm{C}_{2} \mathrm{H}_{2}\right)$ exits a $0.5 \mathrm{~mm}$ and $17.5 \mathrm{~mm}$ diameter nozzle into still air at $300 \mathrm{~K}$ and $1 \mathrm{~atm}$. The axial velocity and axial locations are compared, where the jet centerline mass fraction drops to the stoichiometric value for the initial jet velocities of $8.5 \mathrm{~m} / \mathrm{s}$ and $0.14 \mathrm{~m} / \mathrm{s}$. The viscosity of acetylene at $300 \mathrm{~K}$ is $1.036 \times 10^{5} \mathrm{~kg} \mathrm{~m} \cdot \mathrm{s}$. Its density is $1.1 \mathrm{~kg} / \mathrm{m}^{3}$. The $0.5 \mathrm{~mm}$ - nozzle diameter is the real small nozzle in the combustion thermal spray gun and the $17.5 \mathrm{~mm}$ nozzle diameter is the equivalent nozzle of 20 small real nozzles distributing inside of this diameter.

\section{Solution}

The molecular mass of $\mathrm{C}_{2} \mathrm{H}_{2}$ is lighter that of air (MW = $26.038 \mathrm{~kg} / \mathrm{kmol}$ and $28.85 \mathrm{~kg} / \mathrm{kmol}$, respectively). The constant-density jet solutions can be applied to this problem. Designating the $0.5 \mathrm{~mm}$ - nozzle diameter, $8.5 \mathrm{~m} / \mathrm{s}$ exiting velocity as case I and the $17.5 \mathrm{~mm}$ - equivalent nozzle diameter, $0.14 \mathrm{~m} / \mathrm{s}$ as case II, the jet Reynolds numbers are:

$$
\operatorname{Re}_{j, \mathrm{I}}=\frac{\rho v_{e, \mathrm{I}} R}{\mu}=\frac{1.1 \times 8.5 \times 0.00025}{1.036 \times 10^{-5}}=225.6
$$

and

$$
\operatorname{Re}_{j, \mathrm{II}}=\frac{\rho v_{e, \mathrm{II}} R}{\mu}=\frac{1.1 \times 0.14 \times 0.00875}{1.036 \times 10^{-5}}=130.1
$$

The dimensionless centerline velocity decay is obtained from Eq. 2. The results are shown in Table 1 and Fig. 1.

TABLE 1 CENTERLINE VELOCITY DECAY OF NON-REACTING, LAMINAR ACETYLENE JET

\begin{tabular}{|l|l|l|l|l|l|l|l|l|l|l|l|}
\hline Jet centerline $(\mathrm{mm})$ & $\mathrm{o}$ & 10 & 20 & 30 & 40 & 50 & 60 & 70 & 80 & 90 & 100 \\
\hline Velocity Decay $v_{x, 0} / v_{e}$ & 1 & 1 & 1 & 0.705 & 0.529 & 0.423 & 0.353 & 0.302 & 0.264 & 0.235 & 0.212 \\
\hline
\end{tabular}

\section{CALCULATED PARAMETERS FOR THE SPREADING ANGLE IN A LAMINAR JET}

The spreading angle is determined by combining Eq. 3 and 4 to yield:

For the equivalent flame jet, the spreading angle is

$$
\alpha=\tan ^{-1}\left[r_{1 / 2} / x\right]=\tan ^{-1}\left[2.97 / \operatorname{Re}_{j}\right]=1.3078^{0}
$$

The whole spreading boundary is

$$
\beta \approx 2.5 \alpha=3.2695^{\circ}
$$

Fig. 4 shows flame lengths in the extinguishing process of the thermal spray flame.

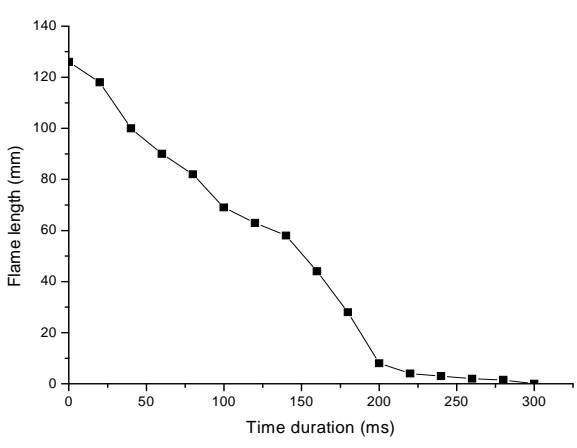

Fig. 4 Flame lengths in the extinguishing process 
VII. Diffusion flame jet lengths for thermal spray jets

In the experiments, the pure acetylene jets spray out and mix with the protective air jet of the nozzle. In the space, the equivalent jet diameter is about $17.5 \mathrm{~mm}$ from the fuel nozzles [6] . The equivalent diameter of the protective air is $6 \mathrm{~mm}$. The volumetric flow-rates are 1-12 ( $/ / \mathrm{min})$ and 17.5 ( $\mathrm{l} / \mathrm{min}$ ) respectively.

The equivalent jet velocities and the Reynolds numbers are:

For the equivalent fuel velocities:

$$
\bar{v}_{\text {fuel }}=\frac{4 Q}{\pi d_{\text {fuel }}^{2}}=\frac{4 \times Q \times 10^{-3}}{\pi \times 0.017^{2} \times 60}=(0.0734 \mathrm{~m} / \mathrm{s}-0.8811 \mathrm{~m} / \mathrm{s})
$$

For equivalent air velocity

$$
v_{\text {air }}=\frac{4 Q}{\pi d_{\text {air }}^{2}}=\frac{4 \times 22.5 \times 10^{-3}}{\pi \times 0.004^{2} \times 60}=29.86(\mathrm{~m} / \mathrm{s})
$$

Reynolds numbers for the fuel jet:

$\operatorname{Re}_{\text {fuel }}=\frac{\rho v r_{j}}{\mu}=\frac{1.161 \times(0.0734 \mathrm{~m} / \mathrm{s}-0.8811 \mathrm{~m} / \mathrm{s}) \times 0.0085}{0.96 \times 10^{-6}}=(754-9058)$

For the air

TABLE 2 EQUIVALENT JET PARAMETERS

\begin{tabular}{|l|c|c|}
\hline & $\begin{array}{l}\text { Equivalent } \\
\text { air jet }\end{array}$ & $\begin{array}{l}\text { Equivalent } \\
\text { fuel jet }\end{array}$ \\
\hline $\begin{array}{l}\text { Nozzle radius } \\
(\mathrm{m})\end{array}$ & 0.002 & 0.00875 \\
\hline $\begin{array}{l}\text { Volumetric } \\
\text { flow-rate }(l \\
/ \mathrm{min})\end{array}$ & 22.5 & $1-12$ \\
\hline Velocity $(\mathrm{m} / \mathrm{s})$ & 29.86 & $\begin{array}{l}(0.0734- \\
0.8811)\end{array}$ \\
\hline $\begin{array}{l}\text { Reynolds } \\
\text { numbers }\end{array}$ & 44124 & $\mathbf{( 7 5 4 - 9 0 5 8 )}$ \\
\hline
\end{tabular}

$$
\operatorname{Re}_{\text {air }}=\frac{\rho v r_{j}}{\mu}=\frac{1.293 \times 29.86 \times 0.002}{1.75 \times 10^{-6}}=44124
$$

So the flow mixture of acetylene and air in the fuel nozzle is turbulent flow. Table 2 shows the calculation results.

According to the experiments [6], the flame lengths are nearly liner to the flow-rate at the fuel nozzle exit.

\section{FLAME EXTINGUISHING EXPERIMENT IN AN ACETYLENE-AIR FLAME JET}

When the fuel supply is stopped, the flame of thermal spray will extinguish. Because no extra pressure exists in the tube, the remaining acetylene will flow out under $1 \mathrm{~atm}$ atmosphere. The flow-rate of the fuel entering the flame will be reduced. This kind of flame flow is more likely to be a laminar flow in thermal spray. So the laminar flame speeds in combustion thermal spray can be obtained by this method.

Fig. 3a-n are the flame photos of thermal spray in an extinguishing process. The image interval is $20000 \mu$ s or 20 ms and exposure time is $5 \mu$ s. The initial $200 \mathrm{~ms}$ can be used as the characteristic time of flame extinguishing. It is related with the fuel consume rate.

The average flame extinguishing speed during the $200 \mathrm{~ms}$ can be obtained:

$$
\bar{S}_{\text {exptl }}=\frac{126.11 \mathrm{~mm}}{200 \mathrm{~ms}} \approx 0.63 \mathrm{~m} / \mathrm{s}
$$

\section{CONCLUSIONS}

This paper emphasizes the general characteristics of the velocity, the nozzle-fluid concentration fields of laminar jets and the Reynolds-number dependence of the spreading characteristics. The main conclusions on laminar jet flame are as follows:

(1) The flame jet structure has been obtained and its centerline velocity decay in the combustion thermal spray has been calculated.

(2) The spreading angle of the laminar flame jet has been calculated. The spreading angle can describe the diffusion in laminar jet and it is noticed that this angle is quite small compared with that of turbulent flame jet.

(3) Experimental trials of extinguishing process in combustion thermal spray have been carried out and flame lengths with time duration have been determined.

\section{REFERENCES}

[1] Stephen R.turns. An Introduction to Combustion (M). McGraw-Hill Higher Education, 2000.

[2] S. Gordon, and B.J. McBride. Computer program for calculation of complex chemical equilibrium compositions, rocket performance, incident and reflected shocks, and Chapman-Jouguet detonations. NASA SP-273(R), Interim Revision, March, 1976.

[3] S. P. Burke and T.E.W. Schumann. Diffusion flames. Industrial \& Engineering Chemistry(J). 1928, 20(10): 998-1004.

[4] K. K. Kuo. Principles of Combustion (M). New York: John Wiley\& Sons, 1986.

[5] N. W. Keys, F. G. Roper, P. J. Kayes. A Mathematical Model of Laminar Axisymmetrical Natural Gas Flames. Computers and Fluids (J) 1981, 9: 85-103.

[6] Wenliang Guo. Computational Modelling of the Combustion Spray Process (D). UK: London South Bank University, 2009... 